\section{The Problem of Wilkes Land}

In the United States Exploring Expedition of 1838 Charles Wilkes reported various landfalls near the antarctic circle south of the Indian Ocean. A number of soundings also showed a continental shelf. On this evidence, Wilkes suggested the existence of an antarctic continent and the lands were long referred to collectively as Wilkes Land. D'Urville at the same time found Adélie Land, which appeared to be part of the same coast-line. Subsequent explorations in these waters, principally by Capt. R. F. Scott and Sir Douglas Mawson, failed to establish all Wilkes's landfalls in the position originally assigned. This had led to the suggestion that he was mistaken and the tendency is to restrict the use of the name, Wilkes Land. Prof. W. H. Hobbs in an article in the Geographical Review for October 1932 discusses this problem and publishes a map on which subsequent discoveries have been printed over those of Wilkes. If Wilkes's latitudes were wrong in many cases, his longitudes show considerable correspondence to actual land. Pack-ice prevented his close approach and the distance of his 'lands' had to be estimated. Allowing for the liability to underestimate distances in the remarkably good visibility, and the lack of cross-bearings to fix position, Prof. Hobbs argues that recent work has re-established Wilkes Land in the wider sense and exonerated Wilkes from the charges that have been brought against him. The name is a useful one to embrace many small lands and might well be retained.

\section{Radium from Canadian Pitchblende}

THE Industrial Information Bureau of Canada announces that a new commercial process of radium extraction has been successfully accomplished by R. J. Traill and W. R. MeClelland of the Department of Mines at Ottawa. On account of the high-grade character of the pitchblende ores from the Great Bear Lake area, and partly because of the simplified technique that has been developed, it is believed that the costs of radium production will be considerably less than has hitherto been practicable. Instead of some forty operations involved in the Belgian method, radium salts can now be produced in the Government Laboratory with less than half that number of steps and in six weeks instead of three months. The chief cost in radium separation arises from the necessity of using about three tons of chemicals for the treatment of every ton of ore. The new process has been adapted to treat with almost equal success both siliceous ore and the silver carbonate ore with which pitchblende is found associated in the Great Bear Lake field. Ten tons of ore are estimated to produce about $1 \mathrm{gm}$. of radium. Already some $4,000 \mathrm{gm}$. of radium concentrates have been extracted in the preliminary experimental work. Canada's first radium refinery is now being established at Port Hope, Ontario, to which point the ore will be brought for the extraction of radium and various by-products such as uranium, lead and silver.

\section{The Personality of Britain}

THE valuable synthetic study of prehistoric Britain as an environment of man which Dr. Cyril Fox delivered as a lecture to the First International Congress of Prehistoric and Protohistoric Sciences (see Nature, Aug 13, p. 247), has now been published by the National Museum of Wales under the title "The Personality of Britain : its infuence on Inhabitant and Invader in Prehistoric and early Historic Times" (Cardiff: National Museum and Press Board of the University of Wales, pp. 84, price 2s. 6d.) In a preface, Dr. Fox points out that publication has been undertaken appropriately by the National Museum since not only does Wales form an integral and important part of the highland zone which he differentiates in the course of his argument, but also characteristic examples of the objects of material culture with which he deals may be seen in the galleries of the Museum. The value of the text as published is much enhanced by a full series of distribution maps, most of them based on material which Dr. Fox himself has collected in the course of the past five years and in the preparation of which he has had the assistance of Miss L. F. Chitty. Archæologists will be grateful to the National Museum of Wales for having so speedily made accessible this valuable and comprehensive study of the influences of geographical environment in Great Britain between circa 2500 B.C. and A.D. 1000 .

\section{Tea Cultivation}

TEA is an unusual crop from the point of view of the cultivator because it is necessary to keep the bush in vigorous vegetative growth and at the same time continue to remove the young vegetative shoots, which are plucked by breaking them off with the thumb and forefinger, the bud and the next two open leaves being thus removed. Naturally, therefore, pruning methods, manurial treatments, etc., will be controlled by different considerations than where an orchard tree is cultivated for its flower and fruit production. Interest is now being taken in the cultivation of tea in Malaya, where the central highland regions are being opened up. Mr. E. A. Curtler was therefore sent on tour to Ceylon and India to obtain the most recent information on methods of toa cultivation and manufacture, and his impressions and experiences are embodied in an interesting publication of the Department of Agriculture of the Federated Malay States (General Series No. 9, 1932).

\section{The Psychology of the Family}

Dr. Pryns Hopkans, in the Sociological Review; vol. 24, No. 2, considers the psychology of the family. He reviews the nature of the chief instincts concerned and he stresses their liability to fixation at, or regression to, any of the numerous stages in their development. Consequently, he suggests that in the pre-marital state, moderate promiscuity should be sanctioned as most likely to promote healthy and complete development, and wise choice of the permanent partner. In the 